\title{
Improving the Care of Infants with Neonatal Abstinence Syndrome by Implementing Rooming In
}

\author{
Tammi M. Clutter \\ West Virginia University, tammiclutter@gmail.com
}

Follow this and additional works at: https://researchrepository.wvu.edu/etd

Part of the Maternal, Child Health and Neonatal Nursing Commons, and the Pediatric Nursing Commons

\section{Recommended Citation}

Clutter, Tammi M., "Improving the Care of Infants with Neonatal Abstinence Syndrome by Implementing Rooming In" (2019). Graduate Theses, Dissertations, and Problem Reports. 7388.

https://researchrepository.wvu.edu/etd/7388

This Problem/Project Report is protected by copyright and/or related rights. It has been brought to you by the The Research Repository @ WVU with permission from the rights-holder(s). You are free to use this Problem/Project Report in any way that is permitted by the copyright and related rights legislation that applies to your use. For other uses you must obtain permission from the rights-holder(s) directly, unless additional rights are indicated by a Creative Commons license in the record and/ or on the work itself. This Problem/Project Report has been accepted for inclusion in WVU Graduate Theses, Dissertations, and Problem Reports collection by an authorized administrator of The Research Repository @ WVU. For more information, please contact researchrepository@mail.wvu.edu. 
Improving the Care of Infants with Neonatal Abstinence Syndrome by Implementing Rooming In

Tammi M. Clutter

Follow this and additional works at: https://researchrepository.wvu.edu/etd

Part of the Maternal, Child Health and Neonatal Nursing Commons, and the Pediatric Nursing Commons 
Improving the Care of Infants with Neonatal Abstinence Syndrome

by Implementing Rooming In

Tammi M. Clutter, MSN, PPCNP-BC

DNP Project submitted to the School of Nursing at West Virginia University in partial fulfillment of the requirements for the degree of Doctor of Nursing Practice

\author{
Kendra Barker, DNP, Chair \\ Courtney Sweet, Pharm.D., BCPPS \\ Christine Mott, DNP \\ Terri Marcischak, DNP \\ Department of Nursing
}

Morgantown, West Virginia

2019

Keywords: Neonatal abstinence syndrome, NAS, rooming in, length of stay, pharmacological treatment

Copyright: 2019 Tammi Clutter 


\author{
Abstract \\ Improving the Care of Infants with Neonatal Abstinence Syndrome \\ by Implementing Rooming In
}

Tammi M. Clutter, MSN, PPCNP-BC

Background: Opioid use and drug abuse has led to an increase in fetal exposure to illicit drugs in the United States, putting these infants at risk for developing neonatal abstinence syndrome (NAS). Parental involvement in the care of these infants during their hospitalization has become an essential part of the treatment process

Purpose: The purpose of this project is to implement rooming in for infants with in utero exposure to opioids as a quality improvement practice change.

Methods: A literature search relating to improving the care of infants with NAS was conducted. Educational handouts were provided to staff regarding the practice change, and to the parents that described NAS and the process of rooming in. Rooming in was then initiated and data was collected relating to hospital length of stay (LOS), pharmacologic treatment, and breastfeeding. Feedback for this practice change was conducted with a staff survey.

Results: Data was collected on 19 infants over a 90-day period. This data was compared to hospital averages previously collected. LOS decreased from an average of 14.4 days in the comparison group to 6.11 days in the study group $(\mathrm{P}=0.0004)$. Pharmacological utilization to treat infants with NAS, decreased from $62 \%$ in the comparison group to $5.3 \%$ in the study group $(\mathrm{P}<0.0001)$. Breastfeeding rates at discharge increased from $14.1 \%$ in the comparison group to $26.3 \%$ in the study group $(\mathrm{P}=0.1891)$.

Discussion: The change in LOS and pharmacological treatment was found to be statistically and clinically significant. It is predicted that LOS and use of pharmacological treatment will continue at this current trend if rooming in continues. Breast feeding rates were found to be clinically but not statistically significant. 


\section{Table of Contents}

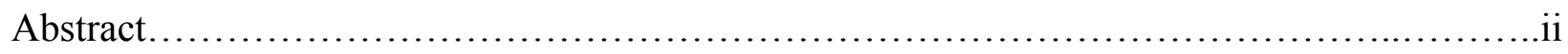

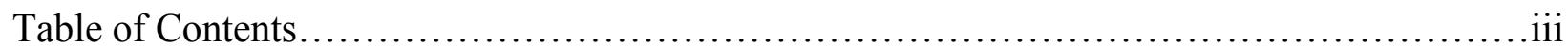

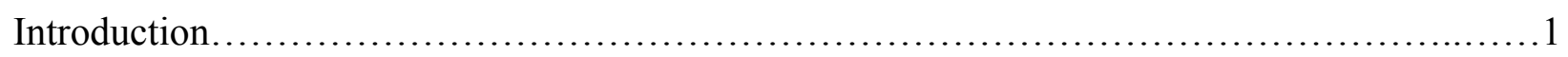

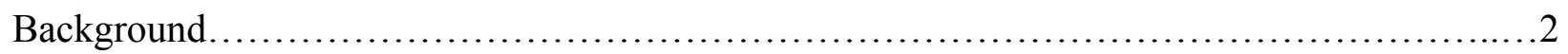

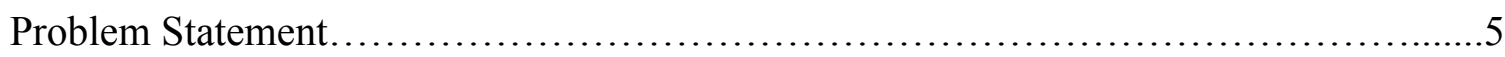

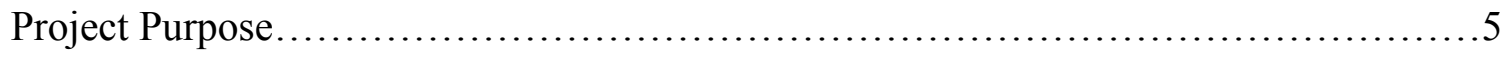

Significance of Proposed Project.....................................................6

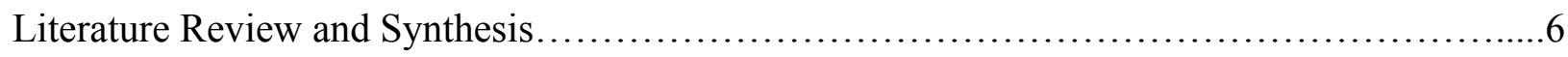

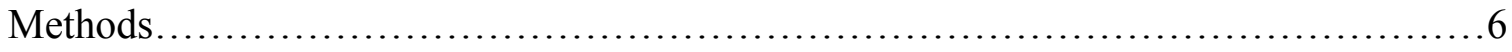

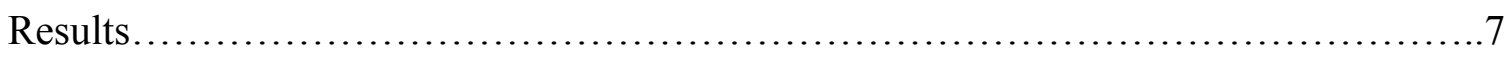

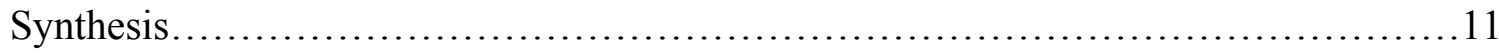

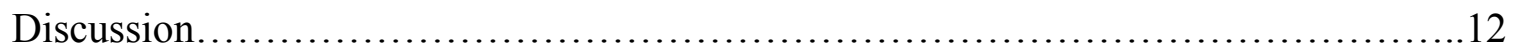

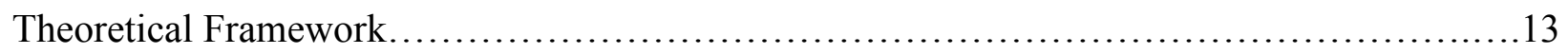

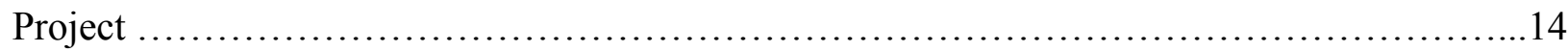

Intervention Plan and Design................................................... 14

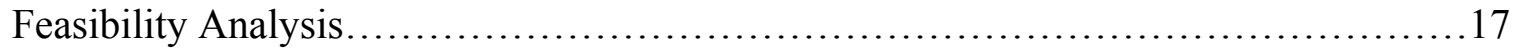

Needs assessment....................................................... 18

Impact and SWOT analysis............................................... 18

Market analysis and budget.................................................. 19

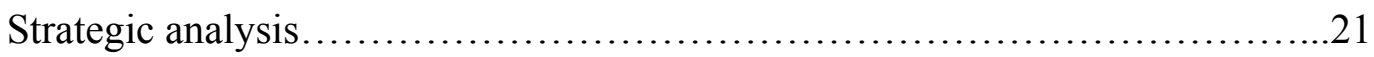

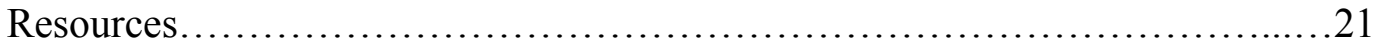


Congruence of organization's strategic plan to project.......................22

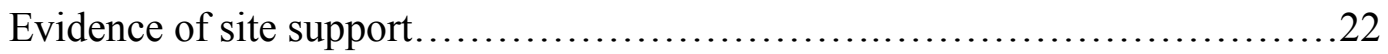

Feasibility and sustainability.............................................22

Project Objectives and Evaluation Plan..........................................23

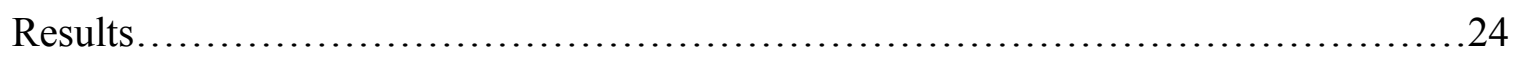

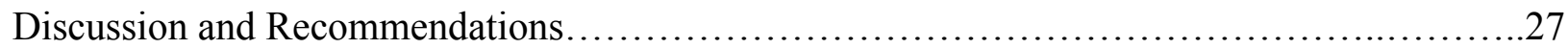

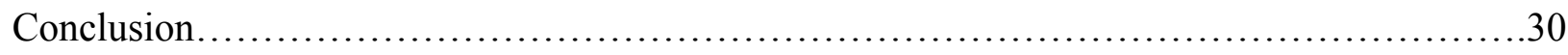

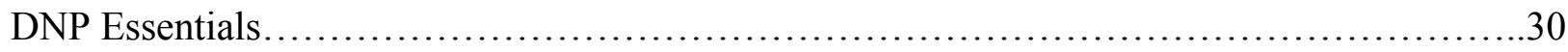

Essential I: Scientific Underpinnings for Practice................................... 30

Essential II: Organizational and Systems Leadership for Quality Improvement and

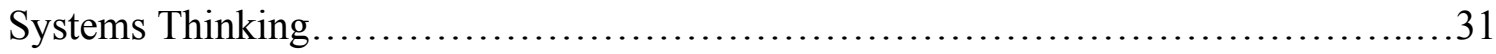

Essential III: Clinical Scholarship and Analytical Methods for Evidence-Based

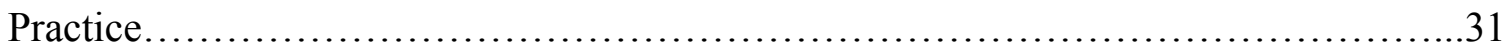

Essential IV: Information Systems/Technology and Patient Care Technology for the Improvement and Transformation of Health Care ..................................32

Essential V: Health Care Policy for Advocacy in Health Care .........................32

Essential VI: Interprofessional Collaboration for Improving Patient and Population

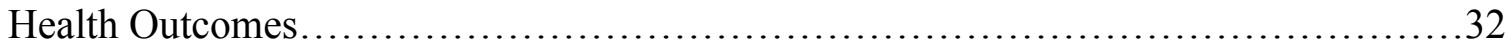

Essential VII: Clinical Prevention and Population Health for Improving the Nation's

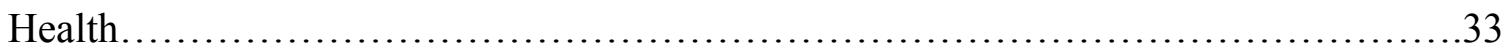

Essential VIII: Advanced Practice Nursing ........................................33

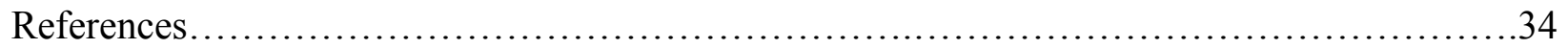

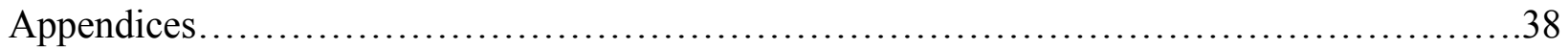


Appendix A: Nursing and Provider Education...............................38

Appendix B: Parent Expectations Handout ...............................43

Appendix C: Staff Survey ...........................................48

Appendix D: Project Timeline........................................49

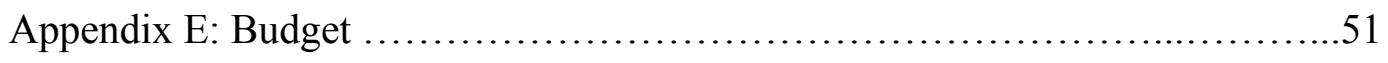

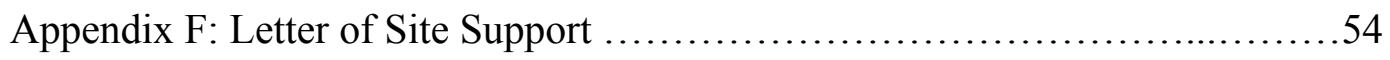

Appendix G: Algorithm for Rooming In ...................................55

Appendix H: Data Tracking Sheet Example ............................56

Appendix I: Data Tracking Sheet Example .............................57

Appendix J: Data Tracking Sheet Example ................................58 


\section{Introduction}

The number of infants suffering from neonatal abstinence syndrome (NAS) secondary to in-utero drug exposure has been on the rise in the United States in the past decade (Patrick, Davis, Lehman, \& Cooper, 2015). This correlates to the opioid drug use epidemic that is sweeping the nation (CDC, 2018). Neonatal abstinence syndrome occurs when a newborn experiences a combination of withdrawal symptoms that affect the musculoskeletal, neurological, and gastrointestinal systems (Kocherlakota, 2014). Any infant with in-utero opioid exposure (as determined by maternal drug testing or reported use) is at risk for NAS and may have varying degrees of symptoms. These infants may not always be formally diagnosed with NAS depending on the severity of their symptoms, so determining exact numbers for this population can be difficult. In West Virginia (WV), according to a report released by the WV Department of Health and Human Resources (DHHR), the incidence rate of NAS in 2017 was 50.6 cases per 1,000 hospital births (2018).

Initial treatment for infants with NAS is usually provided within a hospital's Neonatal Intensive Care Unit (NICU) over an extended period of time until the infant stabilizes for discharge to home. During this treatment period, parents are not typically provided with accommodations to stay with the infant in a private hospital room. As a result, the ability for parents to be involved in the infant's care is limited. The purpose of this quality improvement project is to explore an alternative method of healthcare delivery that would allow parents and atrisk infants to "room in" together. Rooming in is defined as providing a private room accommodation within the hospital for parents to remain with the infant and provide basic care and comfort. During the rooming in process, the bedside nurse performs an assessment, evaluates 
withdrawal symptoms, and monitors the rooming in process. Parents are at the bedside and interactivity with the infant is promoted.

\section{Background}

Opioid use and drug abuse has been rapidly increasing over the last 20 years (CDC, 2018). From 1999 to 2010, the rate of opioid overdoses in women quadrupled (CDC, 2013). The drug crisis does not discriminate and can affect anyone, including pregnant women and their unborn children. The number of newborns who have been exposed to opioid use in utero has been increasing every year, with a fivefold increase nationally between the years 2000 and 2012 (Patrick et al., 2015). It has been estimated that 5.5\% of newborns in the United States have been exposed to illicit drugs while in utero (Wang, 2014). Rates of NAS vary per region of the United States, ranging from 3-16.2 cases per 1,000 hospital births per year in 2012 (Patrick et al., 2015). Parent involvement in the infant's care while hospitalized has been shown to improve outcomes (Grossman et al., 2017; Bernardo et al., 2018). Therefore, it is essential that we explore options to involve parents in the treatment process of neonatal abstinence syndrome.

NAS not only affects newborns and families, it also has a major impact on hospitals, states, and the nation. The total cost of treating infants with NAS increased from $\$ 732$ million in 2009 to $\$ 1.5$ billion in 2012 , with $81 \%$ of total NAS costs being allocated to Medicaid (Patrick et al., 2015). This is a drastic increase in a short time span. With the incidence of drug abuse and NAS continuing to climb, there is no indication that costs associated with the treatment of NAS will decline anytime in the near future.

Several studies have identified the best treatment for these infants, along with the potential complications that NAS and the treatment course may cause. According to the research, non-pharmacological treatment has been identified as one of the best treatment options for 
infants with NAS (Holmes et al., 2016; Wachman et al., 2018; Grossman et al., 2017). Nonpharmacological interventions include rooming in, minimizing environmental stimulation, breastfeeding, swaddling, and holding. Favorable outcomes of these interventions include a decrease in length of hospital stay (LOS), medication use, and healthcare costs.

When an infant with NAS is hospitalized within the NICU, it can create challenges for the parents. This is due, in part, to the traditional design model of many NICUs, which are typically open units with several infants receiving care in a large room. This type of environment may not be conducive to the recovery of an at-risk infant and/or parental involvement in the infant's care. Infants with NAS require a low stimulation, quiet environment; careful and slow handling; and immediate attention when infant signals are given (Hudak \& Tan, 2012). These requirements are difficult to accommodate in a large room with many infants, visitors, and healthcare workers. In a traditional NICU environment, there are limited accommodations for parents to remain at the bedside 24 hours each day. Within this environment, the nurses are responsible for the NAS infant's care and many times the parents see themselves as visitors and not caregivers. A study by Atwood et al. (2016) found that parents often desire to be a part of the infant's care team and not just a bystander to their infant's care, but may be limited by traditional NICU environmental constraints. If the parents are not given the opportunity to become active participants in the child's care due to lack of accommodations, it could have a negative effect on parent/infant bonding and parental confidence when caring for the infant (Atwood et al., 2016; Flacking, Thomson, Axelin, 2016). The lack of bonding and parental involvement may lead to increased stress for the parents and infants (Abdeyazdan et al., 2014).

Increased stress and the emotional toll felt by parents both during the initial hospitalization, and while having an infant with NAS in the NICU, have been explored in the 
literature over the years. Much of the stress felt by the parents manifests as a result of a lack of control over the situation and environment (Atwood et al., 2016; Abdeyazdan et al., 2016; Flacking, Thomson, \& Axelin, 2016). At times parents become angry and irrational, due to both a lack of control and a need for understanding and education about the situation. Rooming in may be a successful way to enhance parental roles and provide some parental control within the situation. Families are educated by nursing regarding care for the infant, what to expect throughout the hospitalization and at home, and about strategies to assist in caring for the infant. The skills learned during the education process can then be practiced while rooming in.

Caring for these infants and families requires a multidisciplinary approach. Nurses are the individuals who provide the most direct patient care throughout the hospital stay, and can significantly influence an intervention aimed at changing healthcare delivery. Attempting a rooming in intervention requires strong nursing support, both for the bedside registered nurses (RNs) and the advance practice registered nurses (APRNs) that provide care within the NICU. By understanding how parent involvement and non-pharmacologic interventions can improve infant and family outcomes, both RNs and APRNs may be able to modify the care provided and increase family involvement. Other professionals within the hospital environment that are instrumental in the success of this project are the various stakeholders, including neonatologists, hospital administrative staff, pharmacists, volunteers, and physical and occupational therapists.

One tool that is frequently used to evaluate the impact of interventions on infants with NAS is the Finnegan scoring system. The Finnegan scoring system evaluates twenty-one signs of opioid withdrawal in the infant including gastrointestinal, central nervous, metabolic, respiratory, and vasomotor disturbances (Hudak \& Tan, 2012). The total Finnegan score is then analyzed by the health care team to guide treatment options. Currently, $95.5 \%$ of hospitals nationwide are 
using the Finnegan scoring system to evaluate and manage infants with NAS (Mehta, Forbes, Kuppala, 2013).

\section{Problem Statement}

Opioid and drug abuse has become a national epidemic, causing the incidence of NAS to increase over the past decade. Care and treatment plans that include parent involvement are required to improve the outcomes for at risk infants and families.

\section{Project Purpose}

The planned quality improvement project was to initiate a rooming in intervention for infants at risk for NAS, in a large hospital in northern West Virginia, which would span the entire hospitalization. Prior to this project, infants would remain with the mothers on the Labor and Delivery Unit after the infant had been birthed. The infant would be evaluated for signs of NAS during this time. If it was determined that the infant exhibited an increasing intensity of withdrawal symptoms and might require pharmacologic therapy, the infant was then separated from the parents and transferred to the NICU for care. The plan for this project was for parents to be able to room in with the infant, assume the care responsibilities of the infant, and participate in the care team.

Outcome measures planned for evaluating the practice change include LOS, pharmacological utilization for treatment of NAS, and breastfeeding incidence at discharge as related to parent involvement in care and rooming in. Data from this project is being compared to data from hospital audits from 2018 that show ninety-two infants were diagnosed with NAS. The average hospital LOS for these infants with NAS within the NICU was 14.4 days in 2018. The use of pharmacological treatment for NAS at this facility involves the administration of morphine, and 57 infants were treated with morphine during 2018. Since 2014, the average 
stabilization dose used in the NAS population at this particular facility has been $0.05 \mathrm{mg} / \mathrm{kg}$ of morphine. The rate of breastfeeding for the NAS population at this organization was $5 \%$ in 2015 , with an increase to $16 \%$ in 2016 . In recent years, the breastfeeding rate has begun to decrease again, with rates being $14.1 \%$ in 2018 . The breastfeeding success rates tend to be lower with the NAS population than the national average of $81.1 \%(C D C, 2016)$.

\section{Significance of Proposed Project}

This project is significant for addressing the need to improve treatment plans for at risk infants and the families. By enabling rooming in, the parents will have the ability to participate in the infant's care. This should decrease the LOS, decrease pharmacological treatment, and increase breastfeeding incidence.

\section{Literature Review and Synthesis}

\section{Methods}

A literature search for implementing changes to the treatment and care of infants with neonatal abstinence syndrome to improve infant and family outcomes was conducted between May 25, 2018 and July 21, 2018. The following databases were utilized: EBSCOhost Medline, Google Scholar, and PubMed. Publication dates used for this literature review ranged from 2012 to 2018. Keywords and phrases used were: 'neonatal abstinence syndrome', 'family involvement', 'maternal drug use during pregnancy', 'parent involvement', 'rooming in', 'breastfeeding', 'parent child bonding', and 'neonatal'. Boolean operators with keywords used were OR 'NAS' and 'rooming in'. Medline and PubMed were both searched using the search mode "find all my search terms." Google Scholar was searched using "article" search mode with specific article names. When searching EBSCOhost Medline and PubMed, limiters were used to narrow searches that yielded thousands of articles. Those limiters were English language, full 
text, peer reviewed, date of publication 2008-2018, and/or US. Inclusion criteria set were retrospective longitudinal, quantitative, and qualitative studies; infants with NAS; pharmacologic and non-pharmacologic treatments for NAS infants; neonatal intensive care unit use; pediatric floor use; stress and emotional effects of separation between hospitalized neonate and the parents; all breastfeeding statuses; and all genders/races/socioeconomic statuses. Exclusion criteria set were neonates requiring intensive and invasive procedures and treatments; postdischarge outcomes because of changes in care; and infants after discharge.

The initial search yielded 1,701 articles before multiple limiters were set. After additional limiters were applied, 126 articles remained. After reviewing the abstracts and eliminating duplicates, the number of articles potentially available for use was reduced to 21 . Upon applying the inclusion and exclusion criteria, the number of studies used for this literature review was nine.

\section{Results}

Nine studies were identified that explored how NAS affects newborns and the parents, as well as interventions to improve the care given and experiences of the newborn and families. The studies included in this literature review were published between the years 2012-2018. Common topics examined in these studies were the effects of rooming in with the NAS infant on various outcome measures including length of stay in the hospital, treatment length, medication dosages utilized, breastfeeding success, and parent involvement. Non-pharmacological interventions to treat and improve care for the NAS infant, parent confidence, and parent/infant stress and bonding were other areas explored in many of the studies.

A retrospective cohort study completed at Boston Medical Center over 11 years was performed on 564 opioid exposed mother-baby dyads who met hospital criteria to breastfeed 
(Schiff et al., 2018). The study examined breastfeeding initiation in the dyads and the continuation of breastfeeding throughout hospitalization until discharge. The study also examined the extent certain hospital characteristics effected the success of breastfeeding. The characteristics were maternal and infant characteristics associated with breastfeeding in nonopioid exposed dyads, maternal factors associated with opioid use disorder, and hospital initiatives to improve breastfeeding rates. Researchers found that as the length of stay for the infant increased, the percentage of mothers who continued to breastfeed declined; cesarean section delivery had a negative correlation with breastfeeding success; and as hospital breastfeeding guidelines relaxed, the odds of an infant receiving breastmilk increased (Schiff et al., 2018).

Another retrospective cohort study completed in Pennsylvania over a three-year time span was performed on 3,725 NAS infants (Short, Gannon, Abatemarco, 2016). The study examined hospital discharge data from 2012-2014 and linked it with birth certificate data. Infant and maternal characteristics were examined and associated with breastfeeding status and the infant's LOS. Researchers found an inverse relationship between breastfeeding and LOS $(p=0.008)$ (Short et al., 2016). This study found that $44.5 \%$ of NAS infants discharged were breastfeeding and the average LOS for a breastfed NAS infant was $9.4 \%$ lower than that of the non-breastfed NAS infants (Short et al., 2016).

A 2016 qualitative study in Europe examined the experience of parental emotional closeness to their infant while hospitalized in a NICU by having the parents fill out a questionnaire (Flacking, Thomson, \& Axelin, 2016). The study was completed at a NICU in each of the following countries: England, Finland, and Sweden. The study evaluated questionnaire responses from 23 parents. A form was created that evaluated moments when the parents felt 
emotionally close to their infant, and how and why they felt close to the infant. Researchers found that parents felt emotional closeness (bonding) with the infant when they were physically close to the infant, involved in the daily activities of caring for the infant, and spent time bonding as a family. The parents in this study stated that stress was felt over healthcare professionals caring for the infant instead of themselves and being unable to protect their infant (Flacking et al., 2016).

In 2016, Holmes et al. completed a cohort study at Children's Hospital at DartmouthHitchcock that examined how improved family-centered care assisted with the treatment of the NAS infant. The study evaluated 163 opioid exposed infants out of 207 that were treated and/or observed at the hospital. During a three-month period in the middle of the study, 10 motherinfant dyads were also evaluated. The researchers utilized the plan-do-study-act (PDSA) model to implement the project. They trained nurses on the modified Finnegan scoring system, ensured the scoring was completed at appropriate times, and standardized physician score interpretation. The researchers provided prenatal education to the families, increased family involvement with monitoring and non-pharmacologic treatment, and treated healthy NAS infants on the pediatric unit versus the NICU. Researchers found that the average length of stay for a nonpharmacologically treated infant was 4.2-4.4 days before and after implementation of rooming in and improved family centered care (Holmes, et al., 2016). After implementation of improved family centered care measures, LOS for pharmacologically treated NAS infants improved from 16.9 days to 12.3 day and cumulative morphine exposure decreased from $13.7 \mathrm{mg}$ to $6.6 \mathrm{mg}$ (Holmes, et al., 2016). When examining the graph included in the study report, it was also noted that LOS spiked when morphine dosages increased. 
Boston Medical Center participated in a cohort study in 2018 by Wachman et al. that included 240 opioid exposed infants. The study utilized the PDSA model to implement a practice change. The change took place over the course of 7 months in three phases. The first phase involved non-pharmacologic care measures and family education regarding the importance of the mothers' participation in care. Phase two included staff education and a transition to methadone as pharmacological treatment when needed. Phase 3 involved implementing a "Cuddler Program" where volunteers hold and comfort the infants and replacing the Finnegan scoring tool with Eat, Sleep, Console scoring. During the study, LOS, pharmacologic treatment, opioid treatment days, and hospital charges all decreased. Family involvement increased during this time. Researchers found a positive correlation between decreased pharmacologic treatment of the NAS infant and total LOS.

Grossman et al. performed a cohort study on 287 NAS infants using the PDSA model at Yale New Haven Children's Hospital in 2017. The study standardized non-pharmacologic care, provided parent education regarding what to expect during hospitalization and their role in the care of the infant, replaced the Finnegan scoring tool with Eat, Sleep, Console scoring, administered morphine for treatment as needed rather than scheduled, and transferred the infants to an inpatient unit versus the NICU. The study found a decrease in LOS, pharmacological treatment, and hospital costs. A positive correlation between decreased pharmacologic treatment of the NAS infant and total LOS was noted.

A quasi-experimental study completed by Bernardo et al. (2018) in Naples, Italy examined salivary cortisol levels in infants that roomed in with parents 24 hours per day (study group) compared to those who roomed in for 14 hours per day (control group). The study examined 40 infants (20 in the control group and 20 in the study group). The study revealed 
decreased cortisol levels in the study group, which implied that the infant whose parents roomed in 24 hours per day experienced lower stress.

Atwood et al. (2016) conducted a qualitative study over a six-month period at the Children's Hospital at Dartmouth-Hitchcock that aimed to improve family-centered care of the NAS infant and families by collecting data on the families' experience and perspective of the hospital stay. Trained professionals conducted open-ended interview questions and the answers were analyzed and divided into themes. Five areas of improvement were identified after the interviews were completed. Those areas were improving parent education over the course of NAS treatment, including the parents in the care team, consistent care and communication, minimizing transfers between units, and external factors. The study concluded that improving parent education, including them in the care team, maintaining consistency, and minimizing transfers are improvements hospitals can make to improve family-centered care.

A quasi-experimental study completed in Iran by Abdeyazdan et al. (2016) examined 50 parents of preterm infants ( 25 in the control group and 25 in the study group).The control group received standard care, while the study group participated in a family support program. This program consisted of a class to educate the families about the NICU, a guided tour of the NICU, and a psychological training session where they were able to share their feelings. Parents in both groups completed a scale used to evaluate parent stress. The study showed that enabling parents to step into their parental role and provide care for the infant while in the NICU, along with providing emotional support, decreased stress was experienced (Abdeyazdan et al, 2016).

\section{Synthesis}

Rooming in has been shown to decrease the LOS, increase the usage of nonpharmacological interventions, decrease the frequency of pharmacological use, and increase the 
incidence of breastfeeding (Holmes et al., 2016; Wachman et al., 2018; Grossman et al., 2017; Short et al., 2016). Length of pharmacological treatment and the dosages of medication used have shown a positive correlation with LOS (Holmes et al., 2016; Wachman et al. 2018, Grossman et al., 2017). The studies reviewed found that when families room in with the infant, and provide non-pharmacologic interventions, a decrease in the utilization of medication to treat NAS was found, resulting in decreased LOS and medical costs. According to Short, Gannon, and Abatemarco (2016), an increased length of stay may lead to a lower incidence of breastfeeding success. Rooming in and other non-pharmacological interventions have been shown to decrease parent/infant stress and improve bonding between the infant and parents, which can increase breastfeeding success.

\section{Discussion}

The increasing NAS population has prompted a need for research regarding treatment and interventions for NAS infants. Choosing the best plan of care for these infants can be difficult, but evidence based practice interventions (such as rooming in) have been shown to reduce pharmacological use, decrease hospital LOS, and lower medical costs. By enabling rooming in, many complications of NAS may be avoided.

As is with all research articles, the previously discussed articles have strengths and weaknesses. One of the strengths of the reviewed articles is that five of the nine articles were completed over an extended period with a large a sample of patients. Another strength is that in six of the studies that involved NAS infants, patients that required treatment for conditions other that NAS were excluded from the study, which controlled for extraneous variables

With regard to weaknesses of the studies, all except for one of the studies examining NAS infants were based in New England. This is limiting the population studied to one 
geographical area in not only the country, but the world as well. Another weakness was that the studies that examined stress in NICU parents/infants and breastfeeding rates had small samples sizes. As a result, this may not accurately depict the population as a whole.

\section{Theoretical Framework}

Introducing change to an organization can be a difficult task, especially when the change is to a process that has been in place for many years. Lewin's Change Theory is a simplistic framework with three basic steps (unfreeze, change, refreeze) that guides the change process (Mindtools, 2018). This change model provides a process that enables the organization to plan ahead in order to manage the change and ease the transition.

During the first step, unfreezing, motivation is generated. At this stage, reasoning is provided as to why change is needed and the organization is prepared and educated to accept the required change. This tends to be the most difficult stage as it forces people out of their comfort zones and creates uncertainty (Mindtools, 2018). For this project, a need to include parents in the care of the increasing numbers of infants at risk for NAS was identified by the NAS Committee Chairs. The literature was reviewed and rooming in was found to be an evidence-based practice intervention to address this need. Nurse educators for each unit disseminated information via email to the staff regarding the rooming in process and its benefits. Email communication was sent to the physicians and nurse practitioners regarding the new practice change as well.

The second step, change, is the portion of the process where exploring potential changes takes place. This happens over a period of time that allows people to begin to embrace the change. At first, people may experience shock and denial that the status quo is changing, which then transitions into anger and rejection of the change. After a period of time, people accept the change and eventually embrace it. During this time, communication regarding how the change 
will be beneficial is essential. Time and proper communication are vital to the success of this step (Mindtools, 2018). Collaborating with those at the organization for ideas can provide motivation and promote staff inclusion to the change. Application of this step was operationalized through staff education, implementing the actual rooming in process, troubleshooting, and requesting feedback. During this practice change, the staff expressed some concerns regarding the change and had some questions that required answering. The steps and expectations of the rooming in process were discussed with individuals and feedback was requested from all the staff involved to promote staff inclusion.

After the change has taken shape and been embraced, the third step, refreezing, begins. During this step, the change has become part of the everyday functioning of the organization and a new normal begins. Providers for the potential rooming in intervention identify infants at risk for NAS. Educational handouts and an algorithm that discusses rooming in and the process for approaching families to continue the practice were provided to the nurse practitioners and physicians. This change theory is simplistic in nature and can easily be applied to a variety of change situations.

\section{Project}

\section{Intervention Plan and Design}

This project involved implementing a practice change. The first step of the project was to review the literature for evidence based practice recommendations. This step involved completing a needs assessment and SWOT analysis as well. Engagement of the staff occurred with the sharing of educational material that was developed specifically for the planned practice change. The project was discussed with each unit's nurse manager, nurse educator, physicians, and nurse practitioners to gain buy in for the project. The educators and managers of four units 
within the hospital (NICU, labor and delivery, PICU, and pediatrics) were provided with education material for the staff. This information was disseminated via email. Education was provided to the physicians and nurse practitioners via email as well. See Appendix A for the education material that was provided to the staff, physicians, and nurse practitioners.

Prior to initiation of the project, parents were able to stay on the labor and delivery unit with an infant known to have had an in-utero drug exposure at risk for NAS. Hospital staff expressed concern that the labor and delivery unit would be unable to safely care for the NAS infant/parent dyad once pharmacological treatment was initiated. This was due to the infant requiring continuous heart rate and respiratory monitoring via an EKG monitor (which is not typically done on this particular unit) and the inability to guarantee smaller nurse to patient ratios for an infant receiving EKG monitoring. As a result, infants with NAS within this study were transferred to another unit for continued rooming in purposes.

Initiation of the project began during step 2. During this step, an informational brochure and a handout explaining NAS, the benefits of rooming in, and non-pharmacological treatment were presented to and reviewed with the parents at the beginning of the hospitalization by the DNP student. See Appendix B for a copy of the handout. If the parents were agreeable, they stayed with the infant 24 hours per day and provided care for the infant after consents to participate in the study were completed. The care included diaper changes, outfit changes, bathing, swaddling, soothing, holding, feeding, administering medications, and any other tasks that were necessary when caring for the infant. The parents were able to leave for appointments and small breaks as needed. At this time a hospital volunteer, nurse, or grandparent was present to care for the infant. 
After initiation of the project, it was determined that the Pediatric Intensive Care Unit (PICU), was a good option for rooming in purposes due to increased feasibility for the intervention (better bed/room availability with infant monitoring capability). Prior to this project, the PICU staff had not regularly cared for infants with NAS, so the staff was not originally included in the implementation plan. As part of the Rapid Cycle Quality Improvement process, the DNP student provided the staff for the PICU with education material and support later in the implementation period than the other hospital staff.

Step 3 involved meeting with the family during the rooming in process to discuss any questions or concerns they had and to see how the experience was progressing. The DNP student performed this step, and kept track of issues that staff and families were experiencing in a journal. Further education was provided at this point when required. Nurses were sent an anonymous 4-question survey via email to evaluate any education gaps relating to NAS and nursing's view of the practice change. See Appendix C for a copy of the survey. Informal faceto-face discussions between the DNP student and nursing took place throughout the project to provide clarification, answer questions, and evaluate overall perception regarding the practice change.

Data collection of LOS, pharmacologic use, and breastfeeding occurred throughout the duration of the project. For pharmacologic use, the DNP student examined the chart for documentation of any pharmacological treatment for NAS. With regard to breastfeeding, the DNP student examined the number of mothers who breastfed their infant during the hospitalization and the number of mother's who were breastfeeding at discharge. Data was entered into tracking flowsheets. A master list of the participants was kept separate from the tracking flowsheets for de-identification of data purposes. See Appendices H-J for the flowsheets 
used. Prior to discharge, the parents had an opportunity to discuss any concerns or obstacles they encountered while rooming in with their infant. This enabled identification of any required modifications to the process for Rapid Cycle Quality Improvement purposes. The project spanned a 90-day period from July to October 2019 with conclusion on October 27, 2019. A project timeline was created when the project was initially planned, and was revised as needed as the project was implemented (see Appendix D).

NAS infants requiring intensive medical treatment and observation were excluded from this project. Infants who initially required a NICU transfer for respiratory distress after delivery, and then were medically cleared to room in were included in the study. Any infant whose parents were deemed ineligible to room in by social services, were also excluded from the project. If at any time it was deemed to no longer be in the infant's best interest to room in with the parents, the infant was removed from the study and transferred to the NICU. The physician and healthcare team made this decision caring for the infant.

Step 4 of the project was to conclude the project, analyze the data, and focus on sustainability of the project. Final data was collected throughout the project and analysis of the data was ongoing, with final data analysis occurring after the conclusion of the study. Since implementation of the practice change, nursing, physicians, and nurse practitioners have expressed an interest in continuing rooming in for NAS infants and parents after the conclusion of the project.

\section{Feasibility Analysis}

After the initial project plan was designed, a feasibility analysis was conducted to determine the need, feasibility, and sustainability for the project. A needs assessment was completed with a SWOT analysis to determine whether a practice change was indicated and if it 
was achievable. A market analysis that included a financial plan and budget was developed. Resources were evaluated for what was available and what was needed.

Needs assessment. There are several challenges that many families with NAS infants experience that were noted with the needs assessment for this project. These include financial difficulties, lack of transportation, and housing difficulties in addition to substance abuse. In many cases, once the parents leave their infant to return home, they struggle to make regular hospital visits. Given the research findings discussed previously in this project proposal, two goals were identified to improve patient and family outcomes: allow rooming in and encourage parents to become involved in the infant's care and treatment while hospitalized. The assessment concluded that increased parental involvement in caring for the NAS infant was needed. Increasing parental involvement would allow infants to avoid separation from the parents during the hospitalization. It was also found that hospital staff and providers would need education about NAS and interventions that are evidence-based.

Impact and SWOT analysis. This project had the potential to create positive changes within the family dynamic that could otherwise be negatively affected by the infant's hospitalization. Breastfeeding and bonding were promoted, while the stress of infant/parent separation was reduced. Through further education and training, the goal was for staff to begin to view these families differently and interact in a more positive manner. Since opioid addiction and NAS are currently popular topics, publishing potential exists with this project.

A SWOT analysis of the proposed project was completed and strengths, weaknesses, opportunities, and threats were identified. The strengths of this project are improvement of infant and parent stress, promotion of family engagement and success, and an increase in parent confidence. These were all a result of the infant rooming in with the family and the family 
becoming more involved in the infant's care. A weakness of this project was an increase in resources required to care for the infant, which has been discussed previously in this paper. Another weakness is a lack of a comparison group with regard to stress, confidence, and bonding. These variables have never been officially assessed in this organization; however, families have expressed concerns related to these variables in the past. One opportunity of this project was that various areas of the hospital were available and capable of caring for these patients. The current rounding team, or another pediatric rounding team, was able to care for this population while a private room was made available on a unit close to the NICU. In addition, physicians and staff were aware of the gaps in caring for the NAS infant, and were seeking changes in the practice. Threats to the success of this project were stigma toward parents with substance use disorder, cooperation of the families, reimbursement for the additional costs of rooming in, and a lack of family support systems outside of the hospital. It can be difficult to stay within the hospital 24 hours a day for the entire hospitalization of the infant. Many times, these parents have treatment appointments and meetings they must attend. There are post-delivery check-ups that the mother must attend as well. As a result, cooperation was a potential issue. In addition, some families lack a support system that promotes a healthy lifestyle for the infant and family during and after hospitalization.

Market Analysis and Budget. Stakeholders have expressed an interest in improving the care for the NAS population by making a practice change. A market analysis was completed to determine the attractiveness and practicality of the practice change. Two advantages of this practice change are improved patient outcomes and the opportunity to enhance the staff knowledge base. This practice change provides educational opportunities for staff regarding how to improve care for the NAS population, identify the need for change, and provide staff with a 
better understanding of the difficulties faced by families caring for infants with NAS. Staff at the organization have previously received education regarding drug use and proper forms of communication with the families.

The cost for caring for infants with NAS can vary from organization to organization. A 2018 study completed within a health care system in Boston, Massachusetts; estimated the average cost of caring for an infant with NAS to be $\$ 37,584$, with the average LOS being 18.7 days (Milliren et al., 2018). A daily charge at this rate would be approximately $\$ 2,000$, which would lead to significant cost savings if days were reduced from the LOS. If the infant requires pharmacological treatment, the LOS and hospitalization costs will increase. If the infant does not require pharmacological treatment, the LOS and hospitalization costs will be lower.

The appropriate professionals needed to provide resources for the NAS population are currently employed (e.g. social workers and care management). However, they must be utilized appropriately to see maximum benefit. The additional space that was required to care for this population was located on other units where rooming in could occur; and measures were in place to accommodate the additional costs related to rooming in per the organization's NAS committee. Costs for the project, aside from hospitality, were minimal. See Appendix E for a copy of the planned budget and resources needed with associated costs. The administrative costs for this project aligned well with the projected budget and equaled $\$ 2,660$. Hospital costs associated with the project were significantly lower than projected. The mother was provided with three meals per day, and meals during the first two days of the mother's hospitalization were covered by insurance. The total cost covered by the hospital equaled $\$ 2,318.86$ for the project, with the budgeted amount being $\$ 13,315$. 
Strategic analysis. Organizational rules and regulations were considered in planning the project design. No regulations were identified that affected this project negatively, or with which the project design conflicted. There were no privacy/confidentiality/security problems present other than those that are found to be typical within this population. All paperwork and identifying information was kept in a locked drawer and password protected computer. Security problems relating to the high risk population in this project, such as; outbursts, threats, and removing the infant form the hospital setting without authorization, were combated by the presence of hospital security personnel and a security band placed around the infant's ankle that could not be removed.

Resources. With this practice change, there were some product and service demands placed on the organization. Additional space and resources were required to accommodate these infants and families. Each infant and family required a private room, additional linens, three meals/day for one caregiver, water, and toiletries. The staff members had additional responsibilities as well. The staff was required to interact with families more frequently once rooming began, which can potentially increase the staff work and stress load. However, the consequences of not making this change could have a negative impact on patient outcomes based on prior research. LOS would not decrease, pharmacologic treatment could continue at a rate higher than necessary, maximum parent/infant bonding would not be achieved, and a more stressful environment for the infant and parents would remain the norm. The stakeholders identified (physicians, advanced practice providers, nurses, pharmacists, and social workers) will continue this practice change after the project is completed. Eventually, a specific unit for this population may be required due to the increasing rate of drug use and NAS births currently taking place in the U.S. 
Congruence of organization's strategic plan to project. The organization's mission is "to improve the health of West Virginians and all we serve through the excellence in patient care, research, and education" (WVU Medicine, 2018). A portion of the organization's vision is "to transform lives and eliminate health disparities through a nationally recognized patientcentered system of care that includes: ...consistent, integrated patient care recognized for delivering the right care in the right place at the right time at all sites, development of new approaches to improve healthcare, including team-based models of care" (WVU Medicine, 2018). This practice change aligns with the organization's mission and vision. The goal of this project was to improve patient care by utilizing research to institute change and improve outcome for infants with NAS. Education was provided to staff and families utilizing evidence based practice to improve the quality of care provided. A multidisciplinary approach was utilized to deliver the care.

Evidence of site support. Members of the organization were approached about the project that resulted in a practice change. Physicians, a pharmacist, nurse practitioners, nursing, and the NAS committee were made aware of the project, and expressed interest in participating in the project. The research counsel, Director of Nursing Services, provided approval and nurse managers of the various units involved. (Letter of Site Support included in Appendix F).

Feasibility and sustainability. Many amenities and accommodations had to be considered when implementing this practice change. Available space within the hospital was required to care for these infants and families. Since these infants require specialized care, a private room on a pediatric or PICU was ideal, as they have experience in caring for the pediatric population. The ability to appropriately monitor the infants once pharmacologic treatment is initiated is essential as well. Careful coordination with the physicians, nurse practitioners, nurse 
managers, nurses, nurse educators, and hospital social services is essential to effectively implementing this practice change. One or more individuals to champion a rooming in practice change is helpful with implementation. These individuals can provide education to the care providers regarding the practice change and initiate the process of discussing rooming in with the parents of the infants.

Many times these families face financial challenges, and buying three meals per day for each caregiver for the entire hospitalization can be a challenge. Providing daily meals for one or both caregivers can assist with this challenge. At this facility, an order is place under the infant's name that requests three meals per day for one caregiver. Access to a shower and personal care items is necessary as well during the hospitalization. For extended stays, access to a washer and dryer helps to limit time away from the infant and combats transportation issues that may be encountered. At this facility, the Ronald McDonald House (where a washer and dryer is located) is within walking distance.

To maintain sustainability of the practice change of rooming in, pediatricians, neonatal/pediatric nurse practitioners, and a nurse clinician in both NICU and the labor and delivery unit were provided with the parent handout explaining rooming in. The care providers were then provided with criteria for determining eligibility for rooming in. See Appendix G for a copy of the criteria provided. Adding a rooming in order to the currently available "NAS order set" is currently being discussed. This would serve as a reminder to nursing and other care providers to consider rooming in for these infants.

\section{Project Objectives and Evaluation Plan}

During this study, there were three primary objectives that were measured as outcomes of rooming in: hospital LOS, pharmacological usage for infants with NAS, and incidence of 
breastfeeding. As planned, the data collected from the study was compared to the hospital data that is already available from previous audits. The DNP student through reviewing chart data within the electronic medical record assessed the outcome variables. Pharmacologic use was measured by reviewing any utilization of pharmacologic treatment (morphine). The number of days spent in the hospital related to NAS was reviewed, as well, by referencing admission and discharge dates. The DNP student also reviewed the documentation for whether or not breastfeeding was present at the time of discharge.

The statistical analysis that was planned for the evaluation of these outcomes was a comparative analysis for evaluating hospital LOS, and pharmacological treatment pre and post intervention, and breastfeeding incidence at discharge. This was accomplished by utilizing an independent t-test to evaluate continuous data, and a fisher test to evaluate categorical data. An electronic, qualitative staff survey was sent by email to the nursing staff to evaluate staff perception of the practice change and education provided; survey completion was anonymous.

Qualitative verbal feedback was collected by the DNP student over the course of the project and documented in a journal for subsequent thematic analysis. As feedback was received, obstacles were met and worked through in a continuous improvement process. This data was used to evaluate and enhance the feasibility and sustainability of the project.

\section{Results}

During the course of the 90-day time span, 23 infants who met inclusion criteria were identified. Four of the identified infants were unable to participate for the following reasons. Mothers of two of the identified infants were unable to commit to rooming in with the infants due to childcare concerns and transportation difficulties. One infant was identified but not approached due to potential safety concerns presented by CPS. One infant was removed from 
participation in the practice change due to removal of infant custody, safety concerns, and social challenges. In the end, data was analyzed for 19 infants that participated.

LOS was analyzed using an independent t-test. In 2018, the mean LOS for infants with NAS $(\mathrm{N}=92)$ was 14.4 days. The LOS for the infants during the 90 -day time span $(\mathrm{N}=19)$ was 6.11 days. This was a decrease of 8.29 days between the comparison group in 2018 and the study group included in this project $(\mathrm{P}=0.0004)$. Of the infants in the comparison group, 57 were treated with pharmacological intervention during their hospitalization and 35 required no pharmacological treatment. That is $62 \%$ of the infants in the comparison group requiring pharmacological treatment. In the study group, one required pharmacological intervention while 18 required no pharmacological treatment. That is $5.3 \%$ of the infants in the study group requiring pharmacological treatment. This is a decrease of $56.7 \%$ from the comparison group to the study group $(\mathrm{P}<0.0001)$. Of the infants in the comparison group, 13 were receiving maternal breast milk for nutrition at discharge and 79 were receiving formula. This is $14.1 \%$ of the infants in the comparison group receiving breast milk at discharge. In the study group, five were receiving maternal breast milk for nutrition at discharge and 14 were receiving formula. This is $26.3 \%$ of the infants in the study group receiving breast milk at discharge. This is an increase of $12.2 \%$ from the comparison group to the study group $(\mathrm{P}=0.1891)$.

A link to an anonymous staff survey was sent via email and 42 nurses responded. When reviewing the responses to the survey, along with verbal feedback collected from the staff and documented in a journal, themes were identified. Themes included observations such as, "rooming in appears to be helpful with parents learning the infants' needs and to care for the infant." Staff members mentioned that there appeared to be improved bonding between the parents and the infants during the hospitalization, and that the infants appear to progress better 
throughout the hospitalization. Some nurses felt that when the parents were present to assist with the infant's care, nursing's workload was improved, while other nurses noted experiencing difficulty with parents remaining in the rooms to care for the infant, and perceived an increase in the nursing workload. Nurses also identified difficulty with some parents participating in the infants' care without prompting. Table 1 depicts the survey respondent's perception of whether or not patient care was improved with rooming in and whether or not there was perceived parent satisfaction. Table 1 also depicts nursing's satisfaction with the practice change.

Table 1

Nursing's Perception of the Impact of the Practice Change

\begin{tabular}{|l|c|c|c|c|}
\hline \multirow{3}{*}{ Patient Care } & Not Improved & $\begin{array}{l}\text { Somewhat } \\
\text { Improved }\end{array}$ & $\begin{array}{l}\text { Moderately } \\
\text { Improved }\end{array}$ & $\begin{array}{l}\text { Greatly } \\
\text { Improved }\end{array}$ \\
\cline { 2 - 5 } & $21 \%$ & $29 \%$ & $21 \%$ & $29 \%$ \\
\cline { 2 - 5 } Parent Satisfaction & $12.5 \%$ & $46 \%$ & $29 \%$ & $12.5 \%$ \\
\cline { 2 - 5 } $\begin{array}{l}\text { Nursing } \\
\text { Satisfaction }\end{array}$ & $42 \%$ & $17 \%$ & $25 \%$ & $17 \%$ \\
\hline
\end{tabular}

When asked for any identification for any further educational needs relating to rooming in for the NAS population, some asked for clarification regarding expectations for the parents while rooming in and the NAS treatment protocol at this particular facility. The staff identified reinforcement of parent education relating to rooming in expectations, appropriate infant care (safe sleeping), importance of accurate NAS scoring, and signs and symptoms of NAS.

When asked what recommendations the nurses had to improve the rooming in process, many nurses expressed the need for smaller nursing assignments when a nurse is providing care 
for an infant with NAS. Others expressed the need for a unit designed specifically for these infants and improved parental support from the staff.

Informal feedback was provided from the parents via face-to-face conversations during and after rooming in occurred. All parents who participated in the conversations reported satisfaction with rooming in, feeling prepared to care for the infant at home, and appropriate parent/infant bonding. Only one parent had difficulty obtaining daily meals. Upon investigation, it was found that the meal order had not been placed in the infant's chart. This was corrected for others participants in the practice change.

\section{Discussion and Recommendations}

When evaluating the data relating to the quality improvement initiative of rooming in, a significant decrease in the LOS and use of pharmacological treatment was found. The change in LOS and pharmacological treatment was found to be statistically and clinically significant as reflected by the P value. If rooming in throughout the entirety of the NAS infant's hospitalization continues, it is predicted that LOS and use of pharmacological treatment will continue to remain lower than previously observed. With the cost analysis referenced earlier, a cost savings of $\$ 2,000$ per day and a decrease in LOS of an average of 8 days, using the rooming in intervention would save $\$ 16,000$ per average NAS infant hospital stay and yield significant healthcare cost savings.

Breast feeding rates at discharge increased from $14.1 \%$ to $26.3 \%$ during this quality improvement project. While not statistically significant, this increase was found to be clinically significant since there was an additional $12.2 \%$ increase in breast feeding rates between the comparison group and the study group. Of note, an extraneous variable for breastfeeding is that there are policies regarding maternal illicit substance use and the ability to breastfeed. If the 
mother is found to be positive for a substance, and a medical professional does not prescribe it, she is discouraged from breastfeeding. In order to improve breastfeeding rates, improved education relating to the impact of breastfeeding and the proper way to wean the infant from breast milk, when appropriate, may be helpful.

Some challenges were encountered during the planning and implementation of the practice change. Not all infants with NAS could be included in the practice change, as some of the infants were born prematurely or experienced other medical problems that prohibited transfer from the NICU setting. Bed availability was an issue at times as well. When the pediatric floor or PICU had a full patient load, rooming in was delayed until a bed became available. One private patient room for parents to learn to care for their infants was available within the NICU. If the other units were full and this room was not already being utilized, the parents and infants were placed in this room temporarily. Another challenge present was related to the custody of the infant. If it was deemed necessary to remove custody of the infant away from the parents by Child Protective Services (CPS), rooming in was interrupted in some cases. At times, parents had other children and responsibilities that prevented them from being able to remain with the infant to room in. In these cases, the infant remained in the NICU setting. Dissemination of the education in a timely manner was challenging at times. In some instances, there was a delay in the education reaching the staff prior to the change taking place.

Based on nursing's feedback, rooming in is viewed as improving the care of these infants and improving parent satisfaction. Reinforcement of parent education and expectations has been identified as a necessity throughout the infant's hospitalization. Clarification for nursing regarding expectations for parents during rooming in and the expectations of the nursing staff is vitally important. Upon reflection, two of the nursing units experienced challenges with the 
variation in their usual patient populations/assignments that likely contributed to the nursing staff feedback. For these two units, providing education related to implementing family-centered care in the NAS population, and reinforcing the type of care that is to be provided by all stakeholders during the rooming in process might help with the implementation of rooming in. Providing more education about the technical aspects of the infant monitoring equipment and the care that NAS infants are expected to receive, might allow for a better transition of rooming in on the labor and delivery unit. Decreasing the nurse's assignment size while caring for an infant with NAS may improve nursing satisfaction relating to rooming in, along with re-education relating to expectations for the parents.

Based on the findings of this project, this practice change should be continued at this facility. A unit specifically designed for the care of these infants and families would be ideal in order to prevent interruption in rooming in when care is transferred to the NICU service, though this would require significant financial investment to build and staff the area. The organization is currently building a new children's hospital. However, the development of a unit for infants with NAS is not currently in the plans.

To continue this change at this facility at this time, a coordinated effort between key stakeholders (physicians, nurse practitioners, nursing, and social services) and the various units involved will be required. Rooming in will need to be discussed with the parents prior to NICU transfer, or immediately after if the NICU transfer came about unexpectedly. Expectations for rooming in will need to be explained, in detail, with the parents. Improved coordination between social services and CPS to allow foster families and biological families to room in after custody removal would be helpful. This should only be complete when there are no safety concerns present. 
This process and plan could be implemented in other hospital settings that treat NAS infants and families. The process for implementing the change would need to be adapted as needed to fit the specific setting, but the general idea of providing private rooms for rooming in to occur should remain. Effective communication, proper planning, and the involvement of key stakeholders could make the practice change successful in any setting.

\section{Conclusion}

Research regarding NAS, treatments of the illness, and complications surrounding the illness and the treatments continue to be studied. Rooming in and increasing parental involvement in the treatment plan and care for the infant has been shown to have a positive effect on the infant and family. Decreased LOS, decreased pharmacological treatment, and increased incidence of breastfeeding are all a result of allowing parents to remain with the infant and participate in the care throughout the hospitalization. Increased bonding and confidence with a decrease in family stress are benefits of these changes as well. As a result of these findings, encouraging the families to stay with the infant during the hospitalization, allowing parents to take over the daily care of the infant, and increasing family participate in treatment planning will result in improved outcomes for the infant and the family.

\section{DNP Essentials}

When planning and implementing this project, all eight DNP Essentials were attained at one point or another in the process. It is discussed below how the eight DNP Essentials incorporated during the process.

\section{Essential I: Scientific Underpinnings for Practice}

Throughout researching parent/infant interaction and bonding, challenges in treating NAS infants, and rooming in; a common theme was revealed. NAS infants typically recover more 
quickly, parent/infant bonding is improved, and less stress is experienced by the parents and infant if rooming in occurs within a private space. With the research in mind along with the ethical considerations and psychosocial aspects, implementing rooming in throughout the entire hospitalization was then next logical step. Lewin's Change Theory was the theoretical framework used to guide the initiation of this practice change project. This framework provided a process to enact the change, ease its transition, and ensure that the change is maintained.

\section{Essential II: Organizational and Systems Leadership for Quality Improvement and}

\section{Systems Thinking}

With the opioid abuse crisis continuing, a need within this health system for improving the care of infants with NAS was identified. The current practice of treating these infants was evaluated and it was a change was identified that could potentially dramatically improve the care for these infants. The change of involving the parents in the daily care of these infants was not as simple as it appeared. The financial cost associated with two additional people staying with the infant had to be taken into consideration, along with space to accommodate these families, training of the care providers regarding the change in practice, and the additional care burden to the staff. All of these factors had to be taken into consideration when determining if this change was not only in the best on the patient and family, but the healthcare organization as well.

\section{Essential III: Clinical Scholarship and Analytical Methods for Evidence-Based Practice}

When comparing the care provided to infants with NAS within this healthcare organization to care provided to infants within other institutions across the world, a trend of increasing parent involvement was present. This trend was backed by research from the US and many other countries and, after critical analysis, was determined to be reliable. A plan was then developed, evaluated for patient safety, determined to be efficient, and was determined to be 
patient centered. Outcomes for evaluating effectiveness were created and a plan for implementation was designed.

Essential IV: Information Systems/Technology and Patient Care Technology for the Improvement and Transformation of Health Care

Throughout the course of the project, data relating to the project participants was collected from the electronic chart. Knowledge of proper use of the electronic charting system was necessary to collect this information timely and efficiently. In addition, knowledge of the EKG monitors, how and/or where that information is transmitted, and the process for notification of abnormal vital signs to the care providers was essential in determining where to safely care for this population.

\section{Essential V: Health Care Policy for Advocacy in Health Care}

With this project, a practice change was implemented and policies were evaluated that may interfere with this change. As part of the NAS Committee, the DNP student advocated for a practice change that, if successful, could potentially be turned into a hospital policy or standard of care. This change reflected ethical and equal treatment of these families who many times feel judgement from others.

Essential VI: Interprofessional Collaboration for Improving Patient and Population Health

\section{Outcomes}

In order to effectively lead this practice change, effective communication skills were required to collaborate with many other professions within the healthcare system. Those involved with this change were physicians, nurse practitioners, nurses, social services, pharmacists, care management, unit clerks, nurse managers, nursing preceptors, and nurse clinicians. These professions all required consultation in order to effectively develop and initiate 
the practice change. Meetings and one-on-one discussions were required, along with recommended changes along the way.

Essential VII: Clinical Prevention and Population Health for Improving the Nation's Health

When caring for this specific population, many social barriers are present that prevent optimal care for infants with NAS. Many times the parents suffer from financial burdens, unstable housing, transportation difficulties, health concerns, and lack a sufficient support system at home. With knowledge of these social difficulties and the difficulties that the parents face when caring for an infant with NAS, a plan to efficiently implement rooming in for the families throughout the entire hospitalization was required. When care from the NICU team was required, a smooth transition from one rooming in area to another without disruption was necessary for the process to be successful. Rooming in enables the parents to practice skills required to care for these infants and provides a safe, reliable environment to stay with the infant. Allowing the parents to stay with the infant decreases the financial burden of traveling to and from the hospital for visitation.

\section{Essential VIII: Advanced Practice Nursing}

Incorporating all of the previously discussed DNP Essentials, achieves Essential VIII. An analysis was completed that evaluated the complexities of caring for this population, the difficulties families encounter, and culturally sensitive solutions were developed. The feasibility and safety of implementing the change was analyzed and evidenced-based care was utilized. Nurses were educated about the care transition and mentoring was provided by addressing concerns relating to the practice change. A therapeutic, judgement-free relationship was developed with the families that promoted trust and understanding. 


\section{References}

Abdeyazdan, Z., Shahkolahi, Z., Mehrabi, T., Hajiheidari, M. (2014). A family support intervention to reduce stress among parents of preterm infants in neonatal intensive care units. Iranian Journal of Nursing and Midwifery Research, 19 (4), 349-352.

Atwood, E.C., Sollender, G., Hsu, E., Arsnow, C., Flanagan, V., Celenza, J., Whalen, B., Holmes, A.V. (2016). A qualitative study of family experience with hospitalization for neonatal abstinence syndrome. Hospital Pediatrics 6 (10), 626-631. doi: 10.1542/hpeds.2016-0024

Bernardo, G.D., Riccitelli, M., Giordano, M., Proietti, F., Sordino, D., Longini, M., Buonocore, G., Perrone, S. (2018). Rooming-in reduces salivary cortisol level of newborn. Mediators of Inflammation, 2018. doi: 10.1155/2018/2845352

Centers for Disease Control and Prevention. (2016). Breastfeeding report card. Retrieved from: https://www.cdc.gov/breastfeeding/pdf/2016breastfeedingreportcard.pdf

Flacking, R., Thomson, G., Axelin, A. (2016). Pathways to emotional closeness in neonatal units - a cross national qualitative study. BMC Pregnancy and Childbirth. doi: $10.1186 / \mathrm{s} 12884-016-0955-3$

Grossman, M.R., Berkwitt, A.K., Osborn, R.R., Xu, Y., Esserman, D.A., Shapiro, E.D., Bizzarro, M.J. (2017). An initiative to improve the quality of care of infants with neonatal abstinence syndrome. Pediatrics, 139 (6). doi:10.1542/peds.2016-3360

Grossman, M.R., Lipshaw, M.J., Osborn, R.R., Berkwitt, A.K. (2018). A novel approach to assessing infants with neonatal abstinence syndrome. Hospital Pediatrics, 8 (1). doi: 10.1542/hpeds.2017-0128

Holmes, A.V., Atwood, A.C., Whalen, B., Beliveau, J., Jarvis, J.D., Matulis, J.C., Ralston, S.L. 
(2016). Rooming-in to treat neonatal abstinence syndrome: improved family centered care at lower cost. Pediatrics, 137 (6). doi: 10.1542/peds.2015-2929

Hudak, M.L., Tan, R.C. (2012). Neonatal drug withdrawal. American Academy of Pediatrics. doi: $10.1542 /$ peds.2011-3212

Kocherlakota, P. (2014). Neonatal abstinence syndrome. Pediatrics, 134 (2), 547-561. doi: $10.1542 /$ peds.2013-5324

Mack, K.A., Jones, C.M., Paulozzi, L.J., Division of Unintentional Injury Prevention, National Center for Injury Prevention and Control. (2013). Vital signs: overdoses of prescription opioid pain killers and other drugs among women - United States, 1999-2010. Centers for Disease Control and Prevention, 62 (26), 537-542. Retrieved from: https://www.cdc. gov/mmwr/preview/mmwrhtml/mm6226a3.htm?s_cid=mm6226a3_w

Mehta, A., Forbes, K.D., Kuppala, V.S. (2013). Neonatal abstinence syndrome management from prenatal counseling to postdischarge follow-up care: results of a national survey. Hospital Pediatrics, 3(4), 317-323. doi: 10.1542/hpeds.2012-0079

Milliren, C.E., Gupta, M., Graham, D.A., Melvin, P., Jorina, M., Ozonoff, A. (2018). Hospital variation in neonatal abstinence syndrome incidence, treatment modalities, resource use, and costs across pediatric hospitals in the United States, 2013 to 2016. Hospital Pediatrics, 8 (1). doi: 10.1542/hpeds.2017-0077

Mindtools Content Team (2018). Lewin's change management model. Mindtools. Retrieved from: https://www.mindtools.com/pages/article/newPPM_94.htm

Patrick, S.W., Davis, M.M., Lehman, C.U., Cooper, W.O. (2015). Increasing incidence and geographic distribution of neonatal abstinence syndrome: United States 2009-2012. Journal of Perinatology, 35 (8), 650-655. doi: 10.1038/jp.2015.36. 
Schiff, D.M, Wachman, E.M., Phillipp, B., Joseph, K., Shrestha, H., Taveras, E.M., Parker, M.G.K. (2018). Examination of hospital, maternal, and infant characteristics associated with breastfeeding initiation and continuation among opioid-exposed mother-infant dyads. Breastfeeding Medicine, 13 (4), 266-273. doi: 10.1089/bfm.2017.0172

Short, V.L., Gannon, M., Abatemarco, D.J. (2016). The association between breastfeeding and length of hospital stay among infants diagnosed with neonatal abstinence syndrome: a population-based study of in-hospital births. Breastfeeding Medicine, 11 (7), 343-349. doi: $10.1089 / \mathrm{bfm} .2016 .0084$

Vivolo-Kantor, A.M., Seth, P., Gladden, M., Mattson, C.L., Baldwin, G.T., Kite-Powell, A., Coletta, M.A. (2018). Vital signs: trends in emergency department visits for suspected opioid overdoses - United States, July 2016 - September 2017. Centers for Disease Control and Prevention, 67 (9), 279-285. Retrieved from: https://www.cdc.gov/mmwr/volumes/67/ wr/mm6709e1.htm

Wachman, E.M., Grossman, M., Schiff, D.M., Philipp, B.L., Minear, S., Hutton, E., Saia, K., Nikita, F., Khattab, A., Nolin, A., Alvarex, C., Barry, K., Combs, G., Stickney, D., Driscoll, J., Humphreys, R., Burke, J., Farrell, C., Shrestha, H., Whalen, B.L. (2018), Quality improvement initiative to improve inpatient outcomes for neonatal abstinence syndrome. Journal of Perinatology. doi:10.1038/s41372-018-0109-8

Wang, M. (2014). Perinatal drug abuse and neonatal drug withdrawal. Retrieved from: https://emedicine.medscape.com/article/978492-overview

WV Department of Health and Human Resources. (2018). DHHR releases neonatal abstinence syndrome data for 2017. Retrieved from: https://dhhr.wv.gov/News/2018/Pages/DHHRReleases-Neonatal-Abstinence-Syndrome-Data-for-2017-.aspx 
WVU Medicine. (2018). Mission and vision. Retrieved from: http://wvumedicine.org/about/ mission-and-vision/ 


\section{Appendices}

Appendix A:

\section{Nursing Education}

To: Unit Managers, Night Shift Supervisors, and Unit Educators

In order to improve the care of our NAS population, I completing a project that will focus on implementing a standard of care that will focus on enabling rooming in throughout an infant's hospitalization for all mothers and caregivers of stable NAS infants being treated in the NICU. While this has been completed from time to time with this population, this project will focus on making this practice the norm for the NICU. Please disseminate the follow information to your nurses and staff.

At this time, mothers and caregivers have the ability to room in with their infant after delivery on MICC. The infant is assessed during this time for signs of withdrawal. Once the infant's NAS scores reach a level that indicates a potential for medication as treatment, the infant is then transferred to the NICU. At this time the infant is separated from the caregivers. Multiple research studies have proven that infants suffering from NAS have a better road to recovery if they are able to room in with the parents during their hospitalization. The length of stay in the hospital, rate of medication use to treat withdrawal, dosages of medication used, and breast feeding rates all show improvement when families are able to stay together. To accommodate this change, the following process will take place:

1. Newborn team on MICC will determine based on Finnegan scores and withdrawal symptoms, whether or not the infant requires transfer of care to the NICU team for further treatment. 
2. The transfer and option for the mother and other caregivers to room in will be discussed with the family by the Newborn team.

3. The family will be provided with a handout outlining the process and expectations of rooming in. See appendix A for a copy of this handout.

4. After the family understands and agrees to the expectations of the handout, the infant will be transferred to a private room on $6 \mathrm{E}$ and the NICU team will begin to follow the infant. At this time the infant will be attached to a monitor to evaluate heart rate and respirations during treatment.

5. Parents will assume responsibility for basic newborn care and will participate/assist in any care that takes place (including therapy sessions, nursing care, and medication administration). Participation in nursing care and medication administration is based upon nursing discretion. The nurse should remain in the room to observe the mother and/or caregivers administer any medications.

6. The nurse will provide education regarding non-pharmacologic measures to calm the infant, such as; swaddling, holding, pacifier use, and rocking. The nurse will, also, provide instruction on how to properly administer medications to the infant.

7. Nurses will continue to perform regular assessments and score the infant as ordered. When possible, the mother and caregivers should be included in the scoring process by the nurse asking the parents questions about withdrawal symptoms that have been exhibited.

8. If at any time the safety of the infant is in question, notify the healthcare team and your charge nurse immediately. 
9. The NICU team will decide when and if it becomes more appropriate for the infant to be removed from the rooming in process and transferred to the NICU.

\section{Physician and Advanced Practice Provider Education}

To: Newborn and NICU Physicians and APPs

In order to improve the care of our NAS population, I completing a project that will focus on implementing a standard of care that will focus on enabling rooming in throughout an infant's hospitalization for all mothers and caregivers of stable NAS infants being treated in the NICU. While this has been completed from time to time with this population, this project will focus on making this practice the norm for the NICU. Please disseminate the follow information to your nurses and staff.

At this time, mothers and caregivers have the ability to room in with their infant after delivery on MICC. The infant is assessed during this time for signs of withdrawal. Once the infant's NAS scores reach a level that indicates a potential for medication as treatment, the infant is then transferred to the NICU. At this time the infant is separated from the caregivers. Multiple research studies have proven that infants suffering from NAS have a better road to recovery if they are able to room in with the parents during their hospitalization. The length of stay in the hospital, rate of medication use to treat withdrawal, dosages of medication used, and breast feeding rates all show improvement when families are able to stay together. To accommodate this change, the following process will take place:

1. Newborn team on MICC will determine based on Finnegan scores and withdrawal symptoms, whether or not the infant requires transfer of care to the NICU team for further treatment. 
2. The transfer and option for the mother and other caregivers to room in will be discussed with the family by the Newborn team.

3. The family will be provided with a handout outlining the process and expectations of rooming in.

4. After the family understands and agrees to the expectations of the handout, the infant will be transferred to a private room on $6 \mathrm{E}$ and the NICU team will begin to follow the infant. At this time the infant will be attached to a monitor to evaluate heart rate and respirations during treatment.

5. Parents will assume responsibility for basic newborn care and will participate/assist in any care that takes place (including therapy sessions, nursing care, and medication administration). Participation in nursing care and medication administration is based upon nursing discretion. The nurse should remain in the room to observe the mother and/or caregivers administer any medications.

6. The nurse will provide education regarding non-pharmacologic measures to calm the infant, such as; swaddling, holding, pacifier use, and rocking. The nurse will, also, provide instruction on how to properly administer medications to the infant.

7. Nurses will continue to perform regular assessments and score the infant as ordered. When possible, the mother and caregivers should be included in the scoring process by the nurse asking the parents questions about withdrawal symptoms that have been exhibited.

8. If at any time the safety of the infant is in question, notify the healthcare team and your charge nurse immediately. 
9. The NICU team will decide when and if it becomes more appropriate for the infant to be removed from the rooming in process and transferred to the NICU.

If this change reveals improvements in the outcomes and treatment for these infants, the intention is for rooming in to continue and become the new norm for NAS infants being cared for by the NICU team. 
Appendix B:

\section{WVU Medicine Children's Hospital}

\section{Parent Expectations for Rooming In with Infants with Neonatal Abstinence}

\section{Syndrome}

\section{Purpose:}

To provide a safe, nurturing, environment where mothers and/or caregivers can stay with their baby and provide care. The medical staff can monitor and provide medication to treat the signs of neonatal abstinence syndrome as necessary.

\section{Objectives:}

1. Keep the mother, caregivers, and baby together as much as possible (ideally 24 hours per day) as long as it is deemed safe.

2. Provide non-judgmental supportive care for the mother, caregivers, and baby.

3. Expect the mother and caregivers (appointed by the mother or Child Protective Services) to provide routine care of the newborn. This includes feedings, diaper changes, bathing, and non-pharmacologic treatment. The mother and/or caregiver may also administer medications to the infant upon observation by the nurse and at the nurse's discretion.

4. Encourage the mother and other caregivers to share in nursing assessments and physical/occupational therapy sessions. This includes encouraging the mother to voice concerns to the medical staff.

\section{Expectations:}


These expectations are meant to empower, encourage, and educate you and other caregivers, as well as help the healthcare team provide the best possible care for your baby while in the hospital and after discharge to home. It has been proven that babies with Neonatal Abstinence Syndrome require less medication, have shorter hospital stays, and are calmer when the mother rooms in.

1. Follow the unit's rules because these rules are meant to keep your baby safe and healthy. I and other caregivers will:

- Maintain a clean and safe environment by ensuring the room remains clean and tidy.

- Will properly wash our hands upon return after leaving the room.

- Will not permit other caregivers or visitors into the room if they have any signs of an illness.

2. You are a valued member of the care team, partner with the healthcare team caring for your baby. I and other caregivers will:

- Learn the symptoms of withdrawal in babies and help the nurse score the severity of your baby's withdrawal symptoms by answering questions about symptoms your baby might be showing. The scoring tool the nurse will be using is call a modified Finnegan score.

- Participate in assessments and medication administration as directed by the nurse.

- Participate in physical and occupational therapy sessions as directed by the therapists. 
- Track feeds, vomits, and diaper changes.

3. Remain fully involved in your baby's care because your baby needs you the most.

As a result, I and other caregivers will:

- Limit time away from my baby to 1 hour at a time and only if necessary (such as, for medical appointments).

- Have another caregiver present of I need to be away for more than 1 hour and will notify the nurse of the plan, including my return time.

- Be present for all feedings and baths.

- Have another caregiver available to help care for my other children if they are present while rooming in.

4. Respect the privacy of others because we respect the privacy of all families.

- I will not discuss, as questions about, or hold any other baby but my own.

5. Openly and honestly communicate with the care team because we need feedback to better care for your baby. I and other caregivers will:

- Notify the care team if I am prescribed a new medication.

- Notify the care team if I use non-prescription medications, such as: over-thecounter medications, herbal/homeopathic remedies, marijuana, or other drugs/medications.

- Bring in and wear a cover (sweater or coat) that will be removed and placed in a bag when come inside from smoking, if I cannot change into clean, smoke free clothes. 
6. Being a new mom is hard and exhausting and asking for help will not reflect badly on you. We are here to help both you and your baby. Because we want to ensure that your baby remains safe, let us know if you become too tired or need assistance. I and other caregivers will:

- Notify the healthcare team if I become too tired or need assistance.

- Always place my baby in the bassinet on his or her back to sleep or when I need rest/sleep. I will NOT sleep with my baby.

7. Learn as much as you can from the healthcare team and ask questions because we want to help provide the best possible future for you, your child, and your family. I and other caregivers will:

- Learn ways to control my baby's environment.

- Learn ways to provide non-pharmacologic therapy such as: positioning, swaddling, rocking, holding, and etc.

\section{Expectations of the Healthcare Team and the Hospital:}

These expectations are meant to give you an idea of what to expect while your baby is hospitalized.

1. The healthcare team will round each morning to discuss your baby's plan for the day. At this time, the team will be looking for your observations about the baby and input about he or she is doing.

2. Your baby's nurse will come into the room to assess for signs of withdrawal every 24 hours using the modified Finnegan score. 
3. The hospital will provide 3 meals per day for 1 primary caregiver while rooming in is occurring. This meal will be delivered to your room after you place an order.

4. You will have access to the Ronald McDonald House during daytime hours to use washers and dryers for your personal laundry. Your nurse can answer any questions you may have.

\section{Calming Techniques:}

If at any time you experience difficulty calming your baby, below are calming techniques that you can use:

1. Holding

2. Rocking

3. Provide a pacifier

4. Swaddling

5. Soothing sounds. Minimize loud noises.

6. If the baby is hot, take off a layer of clothing

7. Feeding

I understand the purpose, objectives, and expectations of rooming in with my baby, and intend to follow the expectations in order to provide my baby with a safe environment and safe care.

\section{Signature:}


Appendix C:

\section{Staff Survey to Evaluate Nursing's Perception of the Rooming In Practice Change}

1. What has been your experience when caring for infants with Neonatal Abstinence Syndrome (NAS) and the families during the rooming in process?

2. Please identify any educational needs that you may still have related to the rooming in process for the NAS population.

3. How do you think this practice change will improve the following?

\begin{tabular}{|l|l|l|l|l|}
\hline & Not at all & Somewhat & Moderately & improved \\
\hline $\begin{array}{l}\text { Patient (Infant) } \\
\text { Care }\end{array}$ & & & & \\
\hline $\begin{array}{l}\text { Parent } \\
\text { Satisfaction }\end{array}$ & & & & \\
\hline $\begin{array}{l}\text { Nursing } \\
\text { Satisfaction }\end{array}$ & & & & \\
\hline
\end{tabular}

4.What recommendations would you make for improvement of the rooming in practice change for NAS infants and the families? 


\section{Appendix D:}

\begin{tabular}{|c|c|c|c|c|c|c|c|c|c|c|c|c|c|c|c|c|c|c|c|}
\hline & $\begin{array}{l}\text { Project } \\
\text { Milestones }\end{array}$ & $07 / 18$ & $08 / 18$ & $09 / 18$ & $10 / 18$ & $11 / 18$ & $12 / 18$ & $01 / 19$ & $02 / 19$ & $03 / 19$ & $04 / 19$ & $05 / 19$ & $06 / 19$ & $07 / 19$ & $08 / 19$ & 09/19 & $10 / 19$ & $11 / 19$ & $12 / 19$ \\
\hline \multirow{9}{*}{ Plan } & Literature Review & $x$ & & & & & & & & & & & & & & & & & \\
\hline & $\begin{array}{l}\text { Present Proposal } \\
\text { to Project Chair }\end{array}$ & $x$ & & & & & & & & & & & & & & & & & \\
\hline & $\begin{array}{l}\text { Organizational } \\
\text { Support/Letter }\end{array}$ & & & & $x$ & & & & & & & & & & & & & & \\
\hline & $\begin{array}{l}\text { Present Proposal } \\
\text { to Committee }\end{array}$ & & & $X$ & & & & & & & & & & & & & & & \\
\hline & $\begin{array}{l}\text { Present Proposal } \\
\text { to NAS Committee }\end{array}$ & & & $X$ & & & & & & & & & & & & & & & \\
\hline & IRB Submission & & & & & & & $x$ & & & & & & & & & & & \\
\hline & IRB Approval & & & & & & & $x$ & & & & & & & & & & & \\
\hline & $\begin{array}{l}\text { Complete } \\
\text { Information for } \\
\text { Preceptors }\end{array}$ & & & & & & & & & & & & $X$ & & & & & & \\
\hline & $\begin{array}{c}\text { Complete } \\
\text { Information } \\
\text { Packet for } \\
\text { Families }\end{array}$ & & & & & & & & & & & & $X$ & & & & & & \\
\hline \multirow{5}{*}{ Execution } & $\begin{array}{l}\text { Provide Education } \\
\text { for Preceptors to } \\
\text { Disseminate }\end{array}$ & & & & & & & & & & & & $x$ & & & & & & \\
\hline & $\begin{array}{l}\text { Provide Education } \\
\text { to Families }\end{array}$ & & & & & & & & & & & & & $x$ & $X$ & $x$ & $x$ & & \\
\hline & $\begin{array}{l}\text { Periodic Family } \\
\text { Sessions }\end{array}$ & & & & & & & & & & & & & $x$ & $X$ & $x$ & $x$ & & \\
\hline & $\begin{array}{l}\text { Attend Monthly } \\
\text { NAS Meeting }\end{array}$ & $x$ & $x$ & $x$ & $x$ & $x$ & $x$ & $x$ & $x$ & $x$ & $x$ & $x$ & $x$ & $x$ & $x$ & $x$ & $x$ & $x$ & $x$ \\
\hline & Data Collection & & & & & & & & & & & & & & $x$ & $x$ & $x$ & & \\
\hline
\end{tabular}




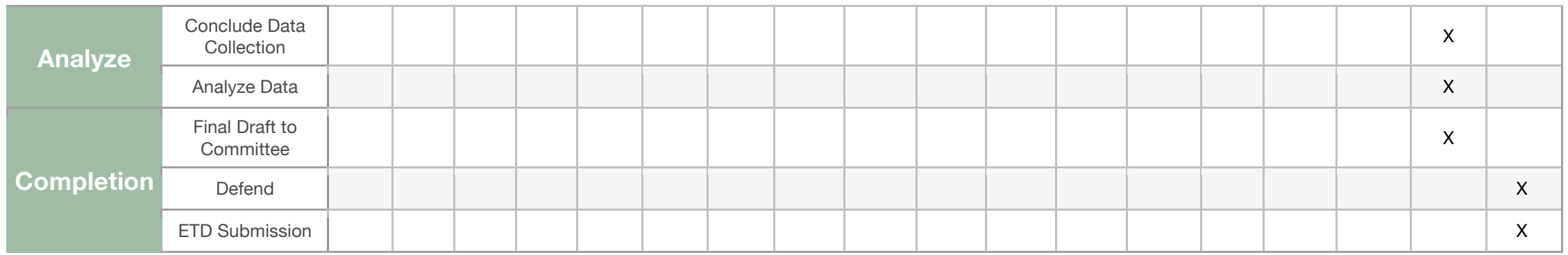


Appendix E:

DNP Project Budget Plan Form and Justification List funds requested for each category including a reasonable justification for expenses. Include total amount of in-kind contributions, if any, for each category.

\begin{tabular}{|c|l|l|}
\hline \multicolumn{1}{|c|}{ BUDGET CATEGORIES } & PERSONAL FUNDS & $\begin{array}{c}\text { ORGANIZATIONAL } \\
\text { CONTRIBUTIONS }\end{array}$ \\
\hline ADMINISTRATIVE COSTS & $\$ 2,520$ & $\$ 0$ \\
\hline AdTmistrative & & \\
\hline
\end{tabular}

Administrative Justification: Administrative costs are comprised of time to provided education to the families, discussion regarding how the hospitalization process and caring for the infant is progressing, tracking the total number of hours the family is spending with the infant, and discussing breast feeding and discontinuing drug use. This will likely take the APRN 3 hours per week to complete for 16 weeks. The nursing staff will provide further education throughout the remainder of the week during regular working hours.

The APRN will need 8 hours to compile information and prepare handouts for the families. Average APRN salary: \$45/hour; $(\$ 45 \times 3 \times 16$ weeks $)+(\$ 45 \times 8$ hours $)=\$ 2,520$ (This time will be voluntary and not paid by any party).

\begin{tabular}{|l|l|l|}
\hline MARKETING & $\$ 0$ & $\$ 0$ \\
\hline Marketing Justification: No marketing plans at this time. & \\
\hline EDUCATIONAL MATERIALS/ & $\$ 0$ & $\$ 0$ \\
INCENTIVES & & \\
\hline
\end{tabular}

Educational Materials/Incentives Justification: Staff education will be completed in CBL form during work hours. As a result, no additional time or money will be required. Cost of 
materials and time to prepare education cover under Administrative Costs and Project Supplies.

\begin{tabular}{|l|l|l|}
\hline HOSPITALITY (food, room rentals, & $\$ 0$ & $\$ 13,315$ \\
etc.) & & \\
\hline
\end{tabular}

Hospitality Justification: In order to accommodate families "rooming in" with and providing care for their infant, the organization will incur certain costs. These costs will include linen (use and laundering) and 3 meals per day for 1-2 family members. The costs account for 2 parents staying with the infant.

Laundry: $\$ 1.10 /$ pound of laundry. Two family members will use 10.06 pounds of hospital laundry per day with an average stay of 17 days. $\$ 1.10 \times 10.6$ lbs. $\times 17$ days $=\$ 118.19 /$ child Meals: Food vouchers for \$7/parent/meal are typically given to parents when "rooming in" occurs. Which is $\$ 14 /$ meal. $\$ 14$ x 3 meals/day x 17 days $=\$ 714 /$ child Total: $\$ 832.19 /$ child. Approximately 16 infants in will be involved in this project. $\$ 832.19 /$ infant $\times 16$ infants $=\$ 13,315.04$

\section{PROJECT SUPPLIES (office} supplies, postage, printing, etc.) Project Supplies Justification: Computer and internet services are available free of charge. Office supplies, printing (paper and ink), and folders for organization will cost approximately $\$ 50$.

\begin{tabular}{|l|l|l|}
\hline TRAVEL EXPENSES & $\$ 0$ & $\$ 0$ \\
\hline \multicolumn{2}{|l|}{ Travel Expenses Justification: N/A } & $\$ 0$ \\
\hline OTHER & $\$ 0$ & \\
\hline Other Justification: N/A &
\end{tabular}




\begin{tabular}{|l|l|l|}
\hline TOTALS & $\$ 2,570$ & $\$ 13,315$ \\
\hline
\end{tabular}

\section{Financial Plan}

\section{Detailed Budget Description:}

The costs of this quality improvement project will be coved in two ways. First, the hospital will specifically cover the costs incurred under the categories listed as Hospitality and Supplies on the attached Capstone Budget Plan. Second, the APRN will perform the education and administrative role free of charge. As a result, no party will be financially responsible for that portion. Financially speaking, return on investment is minimal. Families staying to sooth, calm, and bond with the infant, will hopefully lead to decreased length of stays. This will lead to decreased patient/family complications and readmissions, while increasing available bed spaces that are needed for the rising number of patients requiring care. Reimbursement for the costs of having families stay with the infants will not be reimbursed by Medicaid unless we can restructure the cost for a bed space for the NAS infant. As of right now, these additional costs will need to be covered by the hospital during this process and once this quality improvement project is completed. The intent of this project is to implement a quality improvement initiative that will improve the health and well-being of not only the infant, but the entire family unit. 
Appendix F:

November 28, 2018

Tammi M. Clutter

WVU Medicine One Medical Center Drive Morgantown, WV 26506

To the WVU Institutional Review Board

The WVUH Research and Evidence-Based Practice Council supports the research project undertaken by Tammi Clutter entitled, "Improving Infant and Family Outcomes: Implementing Changes to the Treatment and Care of Infants with Neonatal Abstinence Syndrome" This is a very important project as it has implications that will help to improve the care that patients receive and support the staff that care for them. All necessary resources will be provided to them as they undertake this project. The project outcomes will be used to revise/modify the program as necessary.

The Research and Evidence-Based Practice Council at WVUH grants you permission to complete your project with the following stipulations:

- 1) Permission is granted based on the project being carried out precisely as defined in your methodology

- 2) Permission is granted contingent upon approval and/or recommendations of the WVU Institutional Review Board

- 3) At the mid-point and at the completion of the study, you are requested to share your findings with the Nursing Research and Evidence-Based Council

Please forward me the WVU IRB approval letter for our files.

Best wishes to your team in this endeavor!

Cordially,

Lya M. Stroupe

Lya M. Stroupe DNP, APRN, CPNP, NEA-BC Manager of Nursing Research and Professional Development/Magnet $\AA$ Program Director/Transition to Practice Program Director Nursing Administration/WVU Medicine One Medical Center Drive/PO Box 8227 Morgantown, WV 26506-8227304.293.1417 stroupel@wvumedicine.org 


\section{Appendix G:}

\section{Rooming In Criteria Algorithm}

Does the infant meet criteria per the NAS

protocol for transfer to the NICU service?

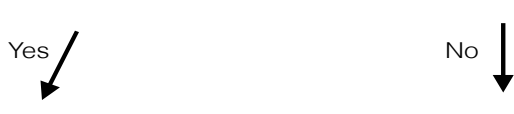

s the infant at least 35 weeks gestation?

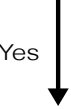

Does the infant require treatment for any medical condition other than NAS?

No

Is the family/caregiver (this includes foster family) willing to room in with the infant throughout the remainder of the infant's hospitalization?

Yes

Review the "Parent Expectation" handout and the NAS brochure with the families. Coordinate with the charge nurse to find room on 6SE or PICU for rooming in.

3.) Transfer the infant to the room and begin rooming in. 
Appendix H:

Tracking Flowsheet for Data Collection

\begin{tabular}{|c|c|c|c|c|c|c|c|c|c|c|c|c|c|}
\hline $\begin{array}{l}\text { Assigned } \\
\text { ID\# }\end{array}$ & $\begin{array}{l}\text { Hospital } \\
\text { LOS (in } \\
\text { days) }\end{array}$ & $\begin{array}{l}\text { Pharm } \\
\text { Treatment } \\
(\mathbf{Y} / \mathbf{N})\end{array}$ & $\begin{array}{l}\text { Pharm } \\
\text { Stblz } \\
\text { Dose } \\
\text { (mg/kg) }\end{array}$ & $\begin{array}{l}\text { Pharm } \\
\text { Duration } \\
\text { (days) }\end{array}$ & $\begin{array}{l}\mathbf{B F} \\
(\mathbf{Y} / \mathbf{N})\end{array}$ & $\begin{array}{l}\text { BF at } \\
D / C \\
(Y / N)\end{array}$ & $\begin{array}{l}\text { BF } \\
\text { (Average } \\
\text { Percent } \\
\text { of Feeds } \\
\text { Per Day) }\end{array}$ & $\begin{array}{l}\text { What } \\
\text { Day of } \\
\text { Life Did } \\
\text { Transfer } \\
\text { to NICU } \\
\text { Occur }\end{array}$ & $\begin{array}{l}\text { What } \\
\text { Day of } \\
\text { Life } \\
\text { Did RI } \\
\text { Start }\end{array}$ & $\begin{array}{l}\text { NICU } \\
\text { LOS } \\
\text { Prior } \\
\text { to RI } \\
\text { Start } \\
\text { (in } \\
\text { days) }\end{array}$ & $\begin{array}{l}\text { Time } \\
\text { Spent RI } \\
\text { (Average } \\
\text { Number } \\
\text { of Hours } \\
\text { Per Day) }\end{array}$ & $\begin{array}{l}\text { RI } \\
\text { (Number of } \\
\text { Days } \\
\text { Completed) }\end{array}$ & Comments \\
\hline Infant \#1 & 17 & $\mathrm{Y}$ & $\begin{array}{c}0.1 \\
\mathrm{mg} / \mathrm{kg}\end{array}$ & 10 & $\mathrm{Y}$ & Y & $80 \%$ & 4 & 5 & 1 & $\begin{array}{c}23.5 \\
\text { hours/day }\end{array}$ & 12 & $\begin{array}{l}\text { Free text entered } \\
\text { here. }\end{array}$ \\
\hline & & & & & & & & & & & & & \\
\hline & & & & & & & & & & & & & \\
\hline & & & & & & & & & & & & & \\
\hline & & & & & & & & & & & & & \\
\hline & & & & & & & & & & & & & \\
\hline & & & & & & & & & & & & & \\
\hline & & & & & & & & & & & & & \\
\hline & & & & & & & & & & & & & \\
\hline
\end{tabular}

- Pharm is Pharmacological, BF is Breastfeeding, RI is Rooming In, LOS is Length of Stay, Stblz is Stabilization, D/C is Discharge 
Appendix I:

Tracking Flowsheet for Data Collection: Infant \#1

\begin{tabular}{|c|c|c|c|c|c|c|c|c|c|c|c|}
\hline $\begin{array}{l}\text { Day of } \\
\text { Life (day } \\
\text { number } \\
\text { from } \\
\text { admission } \\
\text { to } \\
\text { discharge) }\end{array}$ & $\begin{array}{l}\text { Pharm } \\
\text { Treatment } \\
\text { (Y/N) }\end{array}$ & $\begin{array}{l}\text { Pharm } \\
\text { Dose } \\
(\mathrm{mg} / \mathrm{kg})\end{array}$ & $\begin{array}{l}\text { Pharm } \\
\text { Stblz } \\
\text { Day }\end{array}$ & $\begin{array}{l}\text { Pharm } \\
\text { Weaning } \\
\text { Occurred }\end{array}$ & $\begin{array}{l}\text { BF } \\
(\mathbf{Y} / \mathbf{N})\end{array}$ & $\begin{array}{l}\text { \% of } \\
\text { Feeds } \\
\text { Each } \\
\text { Day } \\
\text { That } \\
\text { Were } \\
\text { BF }\end{array}$ & $\begin{array}{l}\text { Day of } \\
\text { Life } \\
\text { Transfer } \\
\text { to NICU } \\
\text { Occurred }\end{array}$ & $\begin{array}{l}\text { RI (Day } \\
\text { of Life } \\
\text { RI } \\
\text { Started) }\end{array}$ & $\begin{array}{l}\text { Time } \\
\text { spent RI } \\
\text { (Number } \\
\text { of Hours } \\
\text { Each } \\
\text { Day) }\end{array}$ & $\begin{array}{l}\text { RI (Each } \\
\text { Day } \\
\text { Completed) }\end{array}$ & Comments \\
\hline 0 & & & & & & & & & & & \\
\hline 1 & & & & & & & & & & & \\
\hline 2 & & & & & & & & & & & \\
\hline 3 & & & & & & & & & & & \\
\hline 4 & & & & & & & & & & & \\
\hline 5 & & & & & & & & & & & \\
\hline 6 & & & & & & & & & & & \\
\hline
\end{tabular}

- Pharm is Pharmacological, BF is Breastfeeding, RI is Rooming In, LOS is Length of Stay, Stblz is Stabilization 
Appendix J:

Tracking Flowsheet for Participant Identification

\begin{tabular}{|c|c|c|c|c|}
\hline $\begin{array}{l}\text { Participant Assigned } \\
\text { ID }\end{array}$ & $\begin{array}{l}\text { Participant Name } \\
\text { (Last Name, First } \\
\text { Name) }\end{array}$ & $\begin{array}{l}\text { Caregiver's Name } \\
\text { (Last Name, First } \\
\text { Name) }\end{array}$ & Phone Number & $\begin{array}{l}\text { Consent } \\
\text { Signed }\end{array}$ \\
\hline Infant \#1 & Smith, Baby Boy & Smith, Jane & $555-555-5555$ & $\mathrm{X}$ \\
\hline & & & & \\
\hline & & & & \\
\hline & & & & \\
\hline & & & & \\
\hline & & & & \\
\hline & & & & \\
\hline & & & & \\
\hline & & & & \\
\hline & & & & \\
\hline & & & & \\
\hline & & & & \\
\hline & & & & \\
\hline & & & & \\
\hline & & & & \\
\hline & & & & \\
\hline & & & & \\
\hline & & & & \\
\hline & & & & \\
\hline & & & & \\
\hline & & & & \\
\hline & & & & \\
\hline
\end{tabular}

